\title{
Clinical course of perianal fistulas in Crohn's disease
}

F Makowiec, E C Jehle, M Starlinger

\begin{abstract}
The clinical course of perianal fistulas and associated abscesses was evaluated prospectively in 90 patients with Crohn's disease. Fistula type, rectal disease, faecal diversion, and immunosuppression were examined as prognostic indicators for fistula healing and recurrence. Median follow up was 22 months. The outcome was evaluated with life table analysis. Prognostic factors were analysed by multiple regression. Inactivation was achieved in all patients. The risks of recurrent fistula activity were $48 \%$ at one year and 59\% at two years. Fistulas were healed in $51 \%$ after two years but reopened in $44 \%$ within 18 months of healing. Faecal diversion and absence of rectal disease decreased recurrence rates $(p=0 \cdot 019 / 0 \cdot 04)$ and increased healing rates $(p=0 \cdot 005 / 0 \cdot 017)$. The outcome in patients with trans-sphincteric fistulas was better than that in those with ischiorectal fistulas but worse than in patients with subcutaneous fistulas ( $p=0.015$ for healing; $p=0.007$ for recurrent fistula activity). After initial treatment about $20 \%$ of the patients were symptomatic and about $10 \%$ had painful events per six month period. Incontinence was rare and did not increase during the study period. Perianal fistulas and associated abscesses can be controlled safely by simple drainage of pus collections. Frequent reinfection and re-opening after healing of fistulas are characteristic. Fistula type, rectal disease, and stool contamination influence the clinical course. Only a few patients, however, have continuous symptoms from perianal fistulas.
\end{abstract}

(Gut 1995; 37: 696-701)

Keywords: Crohn's disease, perianal disease, anal fistula, disease activity.

Perianal fistulas occur in up to $50 \%$ of patients with Crohn's disease. Perianal fistulas and abscesses are sometimes the first manifestation of the disease. Like intestinal disease, perianal Crohn's fistulas may take a chronic recurrent course. Once perianal fistulas have occurred many patients will have symptoms for a long time, frequently with recurrent fistula activity and repeated abscess formation, and therefore require repeated surgical treatment.

A high percentage of healing of perianal Crohn's fistulas has been reported in a few retrospective studies where patients were seen only several years after initial evaluation. ${ }^{12}$
Clinical risk factors for symptomatic recurrence or factors favouring the healing of fistulas have not been clearly identified. It has been suggested that medical treatment or surgical removal of actively diseased bowel may promote healing of perianal fistulas. ${ }^{3}$ In addition, it is well recognised that the chance of healing is higher after the creation of a stool diverting stoma. ${ }^{45}$ However, from these retrospective studies it is difficult to differentiate whether the more rapid healing under ostomy protection is the consequence of changes in rectal disease activity or the lack of stool contamination.

The objective of the prospective study reported here was to describe the clinical course of perianal fistulas in patients with Crohn's disease. We determined the time course of inactivation of perianal fistulas and associated abscesses, the probabilities of healing and recurrent fistula activity, and the risk of re-opening of closed fistulas. Faecal diversion, rectal disease, the type of fistula, and medical treatment were evaluated as prognostic indicators of healing and symptomatic recurrence of fistulas.

\section{Methods}

\section{PATIENTS}

From May 1989 to October 1992, 106 consecutive patients with perianal fistulas were seen in a specialised Crohn's disease clinic in the Department of Surgery at the University of Tübingen. Sixteen patients could not be considered for the study. Nine patients were lost to follow up after initial presentation and therapy. Three patients with a long history of perianal fistulas presented with complete anal incontinence after multiple operations: they underwent proctectomy early after first presentation. The remaining four patients were referred from other centres to receive a transanal advancement flap in order to close the fistulas. The remaining 90 patients (53 women and 37 men) were included in the study and were followed up for a median of 22 months (range 6-44 months) until December 1993. Six hundred and twenty one follow up examinations were documented (mean 6.9 per patient). The patients were also seen regularly in the Department of Medicine of our University hospital. The diagnosis of Crohn's disease (CD) was firmly established in all patients.

The median duration of $C D$ at the time of inclusion in the study was 8 years (range 0-22 years). Nine patients had ileal disease, 31 had Crohn's colitis, and 50 had ileocolitis. Of the 90 patients in our study, $55(61 \%)$ had rectal disease. The mean (SD) duration of perianal

Surgery, Eberhard-
Karls-University,
Tübingen, Germany
F Makowiec
E C Jehle
M Starlinger
Correspondence to:
Professor M Starlinger,
Chirurgische Universitätsklinik,
Hoppe-Seyler-Strasse 3,
D-72076 Tübingen, Germany.
Accepted for publication
23 March 1995


disease was $4.5(4 \cdot 8)$ years. Four of the 90 patients presented without a history of perianal disease. In two of these patients Crohn's disease had not been diagnosed before. Forty one $(47 \%)$ patients had had previous surgery for intestinal disease, and $69(77 \%)$ patients for perianal fistulas or abscesses.

\section{THERAPY OF PERIANAL FISTULAS AND ABSCESSES}

The treatment policy during the study period was observation for asymptomatic fistulas and drainage of symptomatic fistulas and associated abscesses. During the later period selected patients without rectal disease were offered operative fistula closure by means of a rectal advancement flap repair $(n=20)$. The results after this therapy will be reported in a separate paper. ${ }^{6}$ Perianal abscesses were drained by incision (80 abscesses in 45 patients) and, in patients with deep pus collection $(n=25)$, by insertion of a mushroom catheter until macroscopically visible purulent discharge had stopped.

Active fistulas with purulent discharge and communication with the anal canal were drained by seton ( 47 setons in 39 patients) for a mean duration of 5.3 weeks, until purulent discharge or local pain had disappeared.

In seven patients a stool diverting stoma had been performed before their first presentation at our clinic. In another seven patients a diverting stoma was performed for severe perianal disease early during the study period. Two other patients received a stool diverting stoma at first symptomatic recurrence.

\section{THERAPY OF ACTIVE INTESTINAL DISEASE}

All patients in the study were followed for intestinal disease in the Department of Gastroenterology. During the study period, 44 episodes of Crohn's disease were diagnosed in 29 patients by a Crohn's disease activity index (CDAI) $>150$ and typical clinical symptoms. The standardised treatment of these episodes consisted of high dose corticosteroid therapy ( $1 \mathrm{mg}$ prednisone $/ \mathrm{kg}$ body weight/d). The drug regimens were then tapered off and, when possible, stopped. Thirty six patients were given prednisolone $10 \mathrm{mg} / \mathrm{d}$, and six of these also received azathioprine $(100 \mathrm{mg} / \mathrm{d})$. Two patients received azathioprine without steroids. For the evaluation of healing and recurrence rates these 38 patients were classified as a group receiving immunosuppressive therapy.

Nine patients with active fistulas were given

TABLE I Anatomical classification of anal fistulas

\begin{tabular}{|c|c|c|c|}
\hline Fistula type & No (\%) & $\begin{array}{l}\text { No (\%) of } \\
\text { patients with } \\
\text { complex fistulas }\end{array}$ & Group \\
\hline $\begin{array}{l}\text { Trans-sphincteric (including AV) } \\
(15 \mathrm{AV})\end{array}$ & $50(56)$ & $6(12)$ & $\begin{array}{l}\text { Trans-sphincteric fistulas } \\
(n=50)\end{array}$ \\
\hline $\begin{array}{l}\text { Subcutaneous } \\
\text { Intersphincteric } \\
\text { Ischiorectal } \\
\text { Suprasphincteric }\end{array}$ & $\begin{aligned} & 24(26 \cdot 7) \\
& 4(4 \cdot 4) \\
& 11(12 \cdot 2) \\
& 1(1 \cdot 1)\end{aligned}$ & $\begin{array}{l}2(8) \\
0 \\
6(55) \\
0\end{array}$ & $\begin{array}{l}\text { Low fistulas } \\
(n=28) \\
\text { Ischiorectal fistulas } \\
(n=12)\end{array}$ \\
\hline
\end{tabular}

$\mathrm{AV}=$ anovaginal fistula. oral metronidazol (for 2 weeks-3 months). Increased rectal disease activity was treated by enemas (steroids or 5-ASA) in 12 patients. Intestinal resections were performed in 12 patients during the study period for complications of intestinal disease.

METHODS OF FOLLOW UP

Patients with active perianal fistulas or associated abscesses were followed up at short intervals (weekly) until active disease stopped. Afterwards, they were seen at least every six months. Clinical and proctological examination (including proctoscopy) were performed at each visit. When possible (no pain or anal stenosis), endorectal ultrasound (EUS) was performed at each examination (hard cap 7.5 $\mathrm{MHz}$ bifocal multiplane rectal transducer, Kretz Technik, Germany). ${ }^{7}$ When patients underwent surgery for active perianal fistulas or abscesses, EUS was used to locate abscesses before the drainage procedure.

\section{DOCUMENTATION}

At study entry, demographic data and the history of previous perianal fistulas or abscesses were carefully recorded. Activity of fistulas, perianal abscesses, the anatomical type of fistula, and rectal disease activity were classified as described below. The following additional parameters were documented at each presentation: CDAI, medical therapy, and history of any acute episodes of Crohn's disease since the previous visit, presence or absence of a stoma, and surgical therapy of perianal and intestinal disease. Stool incontinence (for air, liquid, or formed stool), pain at rest, and pain at defecation were also recorded. The data were recorded on standardised questionnaires.

\section{CLASSIFICATION OF FISTULA ACTIVITY, FISTULA TYPE AND RECTAL DISEASE}

\section{Perianal fistulas}

These were classified as being active if at least one of the following parameters was present after the exclusion of other painful conditions (proctitis, fissures, haemorrhoids: perianal abscess, fistula with purulent discharge, or severe local pain suggestive of active inflammation.

\section{Fistula type}

Anatomical classification of fistula type was performed as described previously ${ }^{8}$ and reassessed at each follow up visit by proctological and EUS examination. Exploration under anaesthesia was performed only if an operation was necessary for the placement of setons or drainage catheters. In addition, blind fistula tracts into the ischiorectal space without demonstrable internal opening in the anal canal or rectum were defined as ischiorectal fistulas $^{8}$ (Table I). At least one magnetic resonance imaging (MRI) scan of the pelvis was performed in 62 patients. MRI furnished important information on deep abscesses 
(ischiorectal fossa, supralevator space) or the anatomical type of fistulas that were not clearly identified by proctological or EUS examination. ${ }^{9}$ To characterise further the complexity of some of the fistulas (frequency of secondary fistula tracts or multiple ramifications) we evaluated the maximal number of external fistula openings in each patient and classified patients with more than two external openings as having complex fistulas (Table I). A more accurate description was not possible since operative exploration was performed only if necessary for the treatment of active disease, and MRI was not routinely done in all patients.

\section{-.. Rectal disease activity}

Disease activity, as documented by proctoscopy, was classified as highly active in the case of ulceration; moderately active if mucosal friability, mucosal erythema, or a cobblestone pattern were present; or inactive if none of the above mentioned criteria was detectable. Anal stenosis that required bouginage was present in nine patients and ulcerating anal disease in $\mathbf{1 0}$ patients at study entry.

\section{DEFINITIONS}

Inactivation of perianal fistulas and associated abscesses was defined as cessation of purulent discharge from the fistulas and disappearance of perianal pain. Healing was defined as complete closure of the fistula without any sign of activity or pain for at least one month. Re-opening of fistulas was defined as reappearance of perianal fistulas after prior healing. Symptomatic recurrence was the reappearance of active perianal fistulas or associated abscesses after prior inactivation or healing.

\section{STATISTICAL ANALYSIS}

Inactivation of perianal fistulas and abscesses, healing, re-opening, and symptomatic recurrence rates were analysed using Kaplan-Meier survival estimates. Patients were considered at risk until the event occurred (inactivation, healing, recurrence) or until the last follow up examination. Factors influencing healing or symptomatic recurrence were analysed by log rank and Wilcoxon rank tests (univariate analysis). The data underwent further independent analysis using multiple regression according to the proportional hazard model (Cox regression analysis).

\section{Results}

INACTIVATION OF ACTIVE PERIANAL FISTULAS AND ASSOCIATED ABSCESSES

Seventy one of the 90 patients entered the study with active perianal fistulas or associated abscesses. In all 71 , inactivation was achieved between two and 81 weeks later. Median time to inactivation was 6.5 weeks. In $25 \%$ of patients inactivation occurred after four weeks, in $50 \%$ after 6.5 weeks, and in $75 \%$ after 13 weeks.
TABLE II Symptomatic recurrence and fistula healing

\begin{tabular}{|c|c|c|c|c|}
\hline & No & $\begin{array}{l}\text { Symptomatic } \\
\text { recurrence } \\
\text { No (\%) }\end{array}$ & No & $\begin{array}{l}\text { Healing } \\
\text { No (\%) }\end{array}$ \\
\hline All & 80 & $42(53)$ & 90 & $42(47)$ \\
\hline $\begin{array}{l}\text { Faecal diversion: } \\
\text { Yes } \\
\text { No }\end{array}$ & $\begin{array}{l}14 \\
66\end{array}$ & $\begin{array}{r}2(14) \\
34(52)\end{array}$ & $\begin{array}{l}16 \\
74\end{array}$ & $\begin{array}{l}10(63) \\
32(43)\end{array}$ \\
\hline Fistula type: & & & & \\
\hline $\begin{array}{l}\text { Low } \\
\text { Trans sphincteric } \\
\text { Ischiorectal }\end{array}$ & $\begin{array}{l}25 \\
44 \\
11\end{array}$ & $\begin{array}{r}7(28) \\
22(50) \\
7(64)\end{array}$ & $\begin{array}{l}28 \\
50 \\
12\end{array}$ & $\begin{array}{r}18(64) \\
20(40) \\
4(33)\end{array}$ \\
\hline Rectal disease: & & & & \\
\hline $\begin{array}{l}\text { Yes } \\
\text { No } \\
\text { Immunosuppression: }\end{array}$ & $\begin{array}{l}49 \\
31\end{array}$ & $\begin{array}{l}26(53) \\
10(32)\end{array}$ & $\begin{array}{l}55 \\
35\end{array}$ & $\begin{array}{l}24(44) \\
18(51)\end{array}$ \\
\hline $\begin{array}{l}\text { Yes } \\
\text { No }\end{array}$ & $\begin{array}{l}35 \\
45\end{array}$ & $\begin{array}{l}18(51) \\
18(40)\end{array}$ & $\begin{array}{l}38 \\
52\end{array}$ & $\begin{array}{l}16(42) \\
26(50)\end{array}$ \\
\hline
\end{tabular}

\section{RECURRENCE OF FISTULA ACTIVITY}

Ten patients experienced no further active perianal disease during the entire study period. In addition to the 71 patients who entered the study with active fistulas as described above, nine further patients with initially inactive disease developed active disease early during the study. Recurrence of fistula activity after inactivation was studied in these 80 patients. Forty two had at least one recurrence of fistula activity, at a median time interval of 3.8 months after inactivation. The probability of symptomatic recurrence was $35 \%$ after six months, $48 \%$ after one year and $59 \%$ after two years. The crude data on symptomatic recurrence are given in Table II. Only two of $14(14 \%)$ patients with faecal diversion but 34 of 66 $(52 \%)$ patients without ostomy developed symptomatic recurrence. Using independent factor analysis (Cox regression) fistula type $(p=0.007)$, faecal diversion $(p=0.019)$, and rectal disease $(p=0.041)$ appeared as independent prognostic factors: ischiorectal and transsphincteric fistulas recurred more frequently than low fistulas. Patients with faecal diversion had a significantly lower recurrence rate than patients without ostomy. The presence of rectal disease was a risk factor for symptomatic recurrence whereas immunosuppressive therapy did not influence this recurrence rate $(p=0 \cdot 48)$.

\section{SYMPTOMATIC FISTULA RECURRENCE,}

INTESTINAL AND RECTAL DISEASE ACTIVITY

Intestinal disease activity (CDAI) and rectal activity at the time of first symptomatic recurrence $(n=36)$ were compared with the data documented at the examination before recurrence. The mean (SD) time interval between these two examinations was 3.8 (3.6) months. Rectal disease activity and CDAI before and at the time of recurrence are given in Table III.

TABLE III Crohn's disease activity index (CDAI), rectal disease activity, and number of liquid stools at the last follow up before recurrence and at time of recurrence

\begin{tabular}{llll}
\hline & $\begin{array}{l}\text { Before } \\
\text { recurrence }\end{array}$ & $\begin{array}{l}\text { At time of } \\
\text { recurrence }\end{array}$ & $p$ \\
\hline CDAI (mean (SD)) & $88(62)$ & $105(85)$ & 0.33 \\
$\begin{array}{l}\text { Rectal disease activity: } \\
\quad \text { Absent }\end{array}$ & 23 & 21 & \\
$\quad \begin{array}{l}\text { Medium } \\
\text { High }\end{array}$ & 6 & 7 & 0.68 \\
$\begin{array}{l}\text { Mean (SD) no of liquid } \\
\text { stools per wk }\end{array}$ & 3 & 4 & \\
\hline
\end{tabular}


Neither the mean or median CDAI values nor the frequency of rectal disease activity increased. In addition, the number of liquid stools did not increase significantly when fistula activity recurred.

\section{FISTULA ACTIVITY AND FLARE UP OF CROHN'S DISEASE}

At first presentation, 11 of 71 patients with active fistulas had a flare up of Crohn's disease. Four other patients with active fistulas had a flare up 6 to 12 weeks before entering our study and were still taking acute phase therapy at study entry. After the initial inactivation of Crohn's disease, 19 patients with inactive fistulas had 25 'flare ups' of intestinal disease. Five intestinal disease recurrences were accompanied by symptomatic perianal fistula recurrence. In four of these, fistula activity recurred within 12 weeks of the flare up (two patients at four weeks, one at six weeks and, one patient at 12 weeks). The 16 other clinical recurrences were not followed by fistula activity within six months.

\section{HEALING OF FISTULAS}

During the study period perianal fistulas healed in 42 of 90 patients (crude data, Table II). The median time to healing was 11.4 months. The cumulative change of healing was $15 \%$ after six months, $30 \%$ after one year, $51 \%$ after two years, and $69 \%$ after three years. Multiple regression analysis showed that the presence of a stoma was the most powerful factor influencing healing $(p=0.005)$. As with symptomatic recurrence, low fistulas had a better prognosis (higher healing rate) than trans-sphincteric or ischiorectal fistulas $(p=0.015)$. Fistulas healed better in patients without than in those with rectal disease $(p=0.017)$. Medical treatment (immunosuppression or not) had no influence on healing rate $(p=0 \cdot 65)$.

\section{RE-OPENING OF FISTULAS AFTER HEALING}

After healing, perianal fistulas recurred in 16 of the 36 patients available for this evaluation after a median period of five months. The cumulative risk of re-opening was $29 \%$ at six months, $36 \%$ at 12 months, and $44 \%$ at 18 months after healing. The number of included patients and observation times were too small to evaluate risk factors for fistula re-opening.

\section{FREQUENCY OF PERIANAL SYMPTOMS}

Eighty per cent of the patients entered the study with active fistulas, explaining the high frequency of symptomatic disease $(84 \%)$ in the first six month period. After this initial activity, $20-30 \%$ of the patients had symptomatic perianal fistulas during each of the following half year periods. Between $6 \%$ and $18 \%$ only complained at least once of local pain per six month period. Pain at defecation was documented in $71 \%$ of patients with a perianal abscess, in $34 \%$ of active fistulas, and in $5.7 \%$ when fistulas were inactive. Pain at rest was reported in $81 \%$ of patients with an abscess, in $30 \%$ with active fistulas, but in only $4.4 \%$ of those with inactive fistulas.

\section{STOOL INCONTINENCE}

At study entry, 11 patients complained of incontinence, eight for air and three for liquid stool. Three of these patients received an ostomy for active perianal fistulas or abscesses. Only one of the remaining eight patients still complained of incontinence at the last observation (after 35 months). During the study period only two patients developed partial incontinence (for air). Proctectomy was performed in two patients, but not for incontinence. Incontinence was more frequent in patients with a perianal abscess $(11 \%)$ than in patients with inactive perianal fistulas $(3 \cdot 6 \%)$.

\section{Discussion}

By using a standardised treatment and follow up protocol we evaluated the clinical course of perianal fistula disease. Active fistulas and perianal sepsis (abscesses) could initially be controlled effectively in all our patients with simple drainage procedures. However, the symptomatic recurrence rate was high $(59 \%$ within two years). Except in a few patients, intestinal or rectal disease activity was not increased when fistula activity recurred.

At the last follow up visit, $46 \%$ of the patients had healed fistulas. The chance of spontaneous fistula healing was $50 \%$ after two years. However, healing was followed by fistula re-opening or by the development of a new fistula in a comparably high percentage of patients ( $44 \%$ at 18 months after healing). The anatomical type of fistula turned out to be an important prognostic factor influencing both symptomatic recurrence and fistula healing.

Subcutaneous fistulas had the highest chance of healing and the lowest recurrence rate. In contrast, blind ischiorectal fistula tracts without a demonstrable internal opening in the anal canal or the rectum were characterised by low healing and high recurrence rates. The frequent absence of an internal opening in ischiorectal fistulas has previously been identified as an adverse prognostic indicator. ${ }^{10}$

Proximal stool diversion significantly improved the course of the perianal fistulas (lower recurrence rate, higher chance of healing). Rectal involvement of Crohn's disease but not the macroscopic grading of inflammation of the rectal mucosa negatively influenced the course of perianal fistulas. Since the number of liquid stools did not correlate with symptomatic fistula recurrence, the presence of stool per se in the rectum or the passage of stool through the anal canal seem to be local factors that influence fistula activity independently of mucosal inflammation.

Immunosuppressive treatment did not influence the clinical course of perianal fistulas in our patients. Only eight of our patients received azathioprine. A favourable influence of 6-mercaptopurine/azathioprine on perianal 
fistulas has been suggested by others. ${ }^{11}$ This question can only be solved in a controlled trial testing the effect of putative beneficial agents (azathioprine, metothrexate, antibiotics) on the natural course of perianal fistulas in Crohn's disease.

Most patients entered the study with active perianal fistulas or associated abscesses explaining the high frequency of perianal pain in the first six month period. However, the frequencies of perianal symptoms later in the study were low $(20 \%)$ and correlated with recurrent fistula activity. When perianal fistulas were inactive, local pain was reported at only one of 20 follow up visits.

Stool incontinence is one of the main indications for proctectomy in patients with perianal Crohn's disease. Incontinence was relatively rare in our study population. It was transitory and related to active perianal fistulas or abscesses, or related to stool passage through fistula tracts in most cases. Stool incontinence did not worsen during the study period under the conservative local therapy. This confirms the observation of others ${ }^{12}$ that most cases of irreversible stool incontinence in perianal Crohn's disease are not a consequence of the local disease itself but of multiple operations leading to partial or total anal sphincter destruction.

In contrast to the increasing number of prospective study data published on the clinical course of intestinal Crohn's disease, few data have been available regarding perianal fistulas in Crohn's disease. The few retrospective studies on perianal Crohn's disease looked at the final outcome (healing/closure of the fistulas or need for proctectomy) only and lack uniformity as some include anal fissures and skin tags. Buchmann et al ${ }^{1}$ have suggested that the long term course of perianal fistulas in patients with Crohn's disease is relatively benign, resulting in asymptomatic or healed fistulas in most patients followed for 10 years. However, these conclusions are based on a small number of patients, and the 10 year status of only $65 \%$ of the initial study group could be evaluated. Another paper described the long term course in 184 patients with a median follow up of 9.4 years. ${ }^{2}$ Forty per cent of these patients had to undergo proctectomy, but spontaneous healing was observed in $47 \%$ followed by a two year recurrence rate of $35 \%$. Eighty five per cent of the patients without proctectomy were healed at the end of follow up but only $4 \%$ of them had rectal disease. Therefore, patients without rectal involvement had an excellent prognosis: most fistulas healed or were asymptomatic. A similar conclusion was reached in a recent study describing the results of surgical treatment in 27 patients followed for a mean of 16 years. ${ }^{13}$ Patients with ileocaecal disease had an $80 \%$ healing rate after surgical treatment, whereas only four of 15 patients with Crohn's proctocolitis had a favourable long term outcome and 11 patients eventually underwent proctectomy.

The only paper dealing with the long term perspective using lifetable analysis reported a relatively low proctectomy rate. ${ }^{14}$ However, the frequency of rectal involvement in these patients is not given.

Proctectomy may be the ultimate therapeutical possibility in rectal or perianal disease. As mentioned above proctectomy rates vary widely in the published reports. The median follow up in our study is too short to estimate the long term proctectomy rate in our patients with perianal fistulas. Proctectomy was necessary in two of our patients - one with severe anal stenosis and the other with intractable high grade proctitis. However, this low number may not reflect the overall proctectomy rate in patients with distal Crohn's colitis or perianal disease, which is probably higher. ${ }^{2}{ }^{15-17}$

The indications for a more aggressive surgical approach to treat perianal fistulas is a major point of discussion. With various surgical procedures (fistulotomy, partial fistulotomy, drainage), high healing rates were achieved (up to $85 \%$ ) in selected groups of patients. ${ }^{1013} 1618-24$ Some of these papers reported only operations on active fistulas, ${ }^{22}$ others only in patients where an aggressive surgical approach seemed advisable (low lying fistulas and absence of rectal disease as evidenced by rates of rectal involvement in the studied patients as low as $30 \%,{ }^{23}$ as opposed to $61 \%$ rectal involvement in our patients). Furthermore, accurate rates of fistula recurrence are frequently not available mostly because of incomplete data on the length of follow up. Actuarial methods of calculating such end points as healing or recurrence have not been used so far.

We recently began to use excisional surgery with fistula closure (endorectal advancement flap repair) in selected patients with transsphincteric and anovaginal fistulas. ${ }^{6}$ The recurrence rate after flap repair was high, comparable to recurrence rates in the present study. Anovaginal fistulas seem to recur more frequently after local repair than other transsphincteric fistulas. ${ }^{1826}$ Since uncontrolled faecal drainage from the vagina is both uncomfortable and embarrassing for the patient, however, local repair of these fistulas may be worthwhile in these cases. ${ }^{24}$

The results of our prospective follow up indicate that the prognosis of perianal fistulas in Crohn's disease with regard to healing and recurrence may be worse than reported in previous studies. However, active perianal fistulas and associated abscesses could be controlled effectively without aggressive local surgery endangering the anal sphincter. After initial therapy of active fistulas, only a minority of patients had symptoms related to the perianal disease. The proctectomy rate was low in our patients, but this fact may change with a longer follow up period. The clinical course was improved by faecal diversion protecting the rectum and anal canal from contamination. Other risk factors like fistula type and rectal disease give information on prognosis and help planning treatment in these patients. Intestinal or rectal disease activity appeared to influence the activity of perianal disease in a small number of patients only. A special treatment policy to control perianal disease by treating 
intestinal disease activity is not warranted therefore unless rectal disease activity itself gives rise to symptoms such as increased stool frequency or tenesmus.

Parts of this paper have been published in abstract form at the 2nd United European Gastroenterology week 1993, Barcelona Spain and at the annual meeting of the American Gastroenterological Association 1992, New Orleans, USA

1 Buchmann P, Keighley MRB, Allan RN, Thompson H, Alexander-Williams J. Natural history of perianal Crohn's disease. Ten year follow-up: a plea for conservatism. $A m \mathcal{F}$ disease. Ten year follow-up:
Surg 1980; 140: 642-4.

2 Hellers G, Bergstrand O, Ewerth S, Holmström B. Occurrence and outcome after primary treatment of anal fistulae in Crohn's disease. Gut 1980; 21: 525-7.

3 Heuman R, Bolin T, Sjödahl R, Tagesson C. The incidence and course of perianal complications and arthralgia after intestinal resection with restoration of continuity for Crohn's disease. Br f Surg 1981; 68: 528-30.

4 Harper PH, Kettlewell MGW, Lee ECG. The effect of split ileostomy on perianal Crohn's disease. Brf Surg 1982; 69, 608-10.

5 Sher ME, Bauer J, Gorphine S, Gelernt I. Low Hartmann's procedure for severe anorectal Crohn's disease. Dis Colon Rectum 1992; 35: 975-80.

6 Makowiec F, Jehle EC, Becker HD, Starlinger M. Clinical course following transanal advancement flap repair of perianal fistulas in Crohn's disease. Br F Surg 1995; 82: 603-6.

7 Van Outryve MJ, Pelckmans PA, Michielsen PP, Van Maercke YMV. Value of transrectal ultrasonography in Crohn's disease. Gastroenterology 1991; 101: 1171-7.

8 Parks AG, Gordon PH, Hardcastle JD. A classification of fistula-in-ano. $B r f$ Surg 1976; 63: 1-12.

9 Koelbel G, Schmiedt U, Majer MC, Weber P, Jenss H, Kueper K, Hess CF. Diagnosis of fistulae and sinus tracts in patients with Crohn's disease: Value of MR imaging. $A\} R$ 1989; 152: 999-1003.

10 Levien DH, Surrell J, Mazier WP. Surgical treatment of anorectal fistula in patients with Crohn's disease. Surg Gynecol Obstet 1989; 169: 133-6.

11 Korelitz BI, Present DH. Favorable effect of 6-
Mercaptopurine on fistulae of Crohn's disease. Dig Dis Sci 1985; 30: 58-64

12 Alexander-Williams J, Buchmann P. Perianal Crohn's disease. World f Surg 1980; 4: 203-8.

13 Nordgren S, Fasth S, Hultén L. Anal fistulas in Crohn's disease: incidence and outcome of surgical treatment. Int $\mathcal{f}$ Colorect Dis 1992; 7: 214-8.

14 Wolff BG, Culp CE, Beart RW Jr, Ilstrup DM, Ready RL Anorectal Crohn's disease. A long-term perspective. Dis Colon Rectum 1985; 28: 709-11.

15 Keighley MRB, Allan RN. Current status and influence of operation on perianal Crohn's disease. Int $\mathcal{F}$ Colorect Dis 1986; 1: 104-7.

16 Van Dongen LM, Lubbers EJ. Perianal fistulas in patients with Crohn's disease. Arch Surg 1986; 121: 1187-90.

17 Williams JG, Hughes LE. Abdominoperineal resection for severe perianal Crohn's disease. Dis Colon Rectum 1990;

18 Fry RD, Shemesh EI, Kodner IJ, Timmcke A. Techniques and results in the management of anal and perianal Crohn's disease. Surg Gynecol Obstet 1989; 168: 42-8.

19 Sohn N, Korelitz BI, Weinstein MA. Anorectal Crohn's disease: definitive surgery for fistulas and recurrent abscesses. Am f Surg 1980; 139: 394-7.

20 Francois Y, Descos L, Vignal J. Conservative treatment of low rectovaginal fistulas in Crohn's disease. Int $\mathcal{f}$ Colorect Dis 1990; 5: 12-4.

21 Morrison JG, Gathright JB, Ray JE, Ferrari BT, Hicks TC, Timmcke AE. Surgical management of anorectal fistulas in Crohn's disease. Dis Colon Rectum 1989; 32: 492-6.

22 Pritchard TJ, Schoetz DJ, Roberts PL, Murray JJ, Coller JA, Veidenheimer MC. Perirectal abscess in Crohn's disease. Veidenheimer MC. Perirectal abscess

23 Williams JG, Rothenberger DA, Nemer FD, Goldberg SM. Fistula-in-ano in Crohn's disease. Dis Colon Rectum 1991; 34: 378-84.

24 Scott NA, Nair A, Hughes LE. Anovaginal and rectovaginal fistula in patients with Crohn's disease. Br f Surg 1992; 79: $1379-80$.

25 Bayer I, Gordon PH. Selected operative management of fistula-in-ano in Crohn's disease. Dis Colon Rectum 1994; 37: 760-5.

26 Jones IT, Fazio VW, Jagelman DG. The use of transanal rectal advancement flap in the management of fistulas
involving the anorectum. Dis Colon Rectum 1987; 30: 919-23. 